\title{
Memory and language in Hiromi Goto's Chorus of Mushrooms
}

\author{
Eva Pich Ponce \\ epich@us.es \\ Universidad de Sevilla, Spain
}

\begin{abstract}
Hiromi Goto's Chorus of Mushrooms (1994) highlights the difficulties encountered by Japanese when immigrating and living in Canada. This essay focuses on how Hiromi Goto uses linguistic codes to construct cultural identities and to stress the arbitrary nature of stereotypes. It analyzes the importance of memory and translation, which can be seen as both necessary and alienating. It also examines the importance of language and storytelling in the process of constructing one’s identity.
\end{abstract}

Keywords: language, memory, Asian Canadian writing, identity, stereotypes, storytelling

\section{INTRODUCTION}

The remarkable literary activity in Canada since the Second World War has been recognized and celebrated by literary criticism throughout the world. The relationship between collective identity and the perception and representation of the Other constitutes an essential question of contemporary cultural and literary discourse. The literary representation of ethnic minorities is extremely important in order to understand current issues about multiculturalism, nationalism, integration. It is even more significant when considering the emergence of authors writing from within that cultural minority experience. Canadian history and its present situation are rewritten by these new voices that seek their place in the country. As Mari Sasano has pointed out, although the notion of multiculturalism implies the acknowledgement of different cultures, a distinction is generally made between "typical Canadian" and "multicultural”, the latter consisting of "those minorities that are seen as additional to but outside of typical white middle-class majority” (Sasano 1998: 39). Through the analysis of Hiromi Goto's Chorus of Mushrooms (1994), this study aims to examine how Asian-Canadian minorities are representing themselves and how language is used in the construction of social and cultural identities. 
Hiromi Goto was born in Japan and immigrated to Canada with her family when she was three years old. After living on the West Coast for some time, her family moved to Nanton, Alberta. In Chorus of Mushrooms, the author highlights the difficulties encountered by ethnic minorities when trying to find their own identity. It examines the intercultural experience of Japanese Canadians through the lives of three generations of women belonging to the same Japanese family living in Nanton. If the author draws on her own experience to write this narrative, the autobiographical dimension of the text is challenged by the subversion of realism and the destabilization of narrative unity, reliable point of view and coherent character presentation. As Linda Hutcheon has observed in contemporary Canadian novels:

Postmodernism in Canada has suggested a rethinking of realism, and therefore we have a situation in which realism is both challenged and taken seriously. [...] Like fiction, history is viewed through frames, and those frames bring only certain pre-selected things into the foreground of the reader's attention. And this is true of both public and private history (Hutcheon 1988: 21).

In Chorus of Mushrooms, the metafictional dimension of the novel is made evident by the way the narrator refers to the creating process and by the structure of the text itself. The novel appears as a story which is being told by the narrator to her lover. The second personal pronoun, “you”, is used to address the narratee. This interlocutor, who asks the narrator to tell him a "true story", sometimes interrupts the narrative to make comments or to give his opinion. A dialogue on the text itself is thus presented and it foretells some of the reactions Goto's readers may have. As Hutcheon has pointed out, postmodern novelists are very aware of "the twin processes involved in their production: their creation and their reception” (1988: 45). The dialogue between narrator and narratee highlights the interaction that can take place. Although the use of the second person invites the reader to identify with this narratee, the "you" can also be exclusionary, as Emma E. Smith has shown in her study on this novel. Indeed, the second person refers to a particular character, who can speak Japanese, and with whom the non-Japanese-speaking reader cannot assume identity (Smith, 2007: 251).

The different narrative layers used in the novel bring to light different perspectives and challenge any possible unity. Besides the dialogue between the controlling narrator (Murasaki) and her lover, the text intertwines the stories told by Muriel/Murasaki, and by her grandmother Naoe. These are centred on their experiences and recollections. Other stories, such as Japanese legends or journal articles, are embedded within their 
narrations and introduce other voices in the text. The polyphonic nature of the novel, which is also announced in the title, suggests that the approaches to immigrant life in Canada are plural, and cannot be reduced to a sole discourse on immigration and identity.

Moreover, throughout the multi-levelled narrative, the stress is put on interaction. The different voices, fragments and stories that appear in the text complement one another and create an intertextual dialogue. Besides the conversations between the controlling narrator and the narratee, other dialogues take place between Naoe and her granddaughter Murasaki. Their dialogues, written in brackets, appear as telepathic conversations that can take place in spite of the spatial and temporal distance that separates the interlocutors. The metafictional aspect of the novel is further highlighted by the contents of these dialogues where the two narrators speak about the creative process:

Murasaki: Obachan, everyone wants to hear stories. And I can't finish them. They scatter like sheep. Like dust.

Naoe: No need to tie them up. There is always room for beginnings (Goto 1997: 63).

This lack of closure is also a procedure used by Goto in her novel. As the author has explained in an interview, in her fiction: "there is a resistance to the notion of closure for this is not the reality of women's lives. Closure to me is very artificial, contrived and prescriptive. [...] Life narratives are circular and ongoing” (Goto, in Morris 2008: 234).

Goto's novel is characterized by the lack of a time line. As the fictional interlocutor tells the narrator: “'YYou switch around in time a lot,' [...] 'I get all mixed up. I don’t know in what order things really happened” (Goto 1997: 132) ${ }^{1}$. The answer provided by the narrator is extremely significant as it justifies the complex structure of the novel itself:

There isn't a time line. It's not a linear equation. You start in the middle and unfold outward from here. It's not a flat surface that you walk back and forth on. It's like being inside a ball that isn't exactly a ball, but is really made up of thousands and thousands of small panels. And on each panel, there is a mirror, but each mirror reflects something different. And from where you crouch, if you turn your head up or around or down or sideways, you can see something new, something old, or something you've forgotten (132).

According to this definition, the story consists of as a series of mirroring images and of windows opened to different realities and different times. Again, the stress is put on

\footnotetext{
${ }^{1}$ From now on, the references to this edition will be made through the number of the page written in brackets.
} 
plurality, but also on memory and on the capacities of the story to make others aware of what has been forgotten.

Hutcheon has observed that the postmodern writer is inevitably in a "marginal or 'excentric' position with regard to the central or dominant culture, because the paradox of underlining and undermining cultural 'universals' [...] challenges any notions of centrality” (1988: 3). This is even truer when the author is writing from the position of an ethnic minority community. The margin becomes a place of transgression, but also, as Hutcheon points out, the place of possibility (1988: 3). Through their texts, writers try "to trouble, to question, to make both problematic and provisional any [...] desire for order or truth through the powers of the human imagination” (Hutcheon 1988: 2).

The notion of truth is indeed problematic, as Goto's text points out. Truth may be confused with a system of belief specific to a particular culture and time. According to Hutcheon, “what any society calls universal 'truth' is really [...] socially, culturally, economically, and historically particular” (1988: 12). The multiple voices of Goto's novel and the different stories embedded highlight how truth, as identity, is something fluid. It changes with the telling and it also involves the interlocutor's trust and belief. Chorus of Mushrooms combines Japanese cultural references and Canadian ones. It stresses the importance of food and language when approaching a foreign culture and it shows how stories are both a way of getting to know the Other and of constructing one’s history and one's identity.

\section{THE MEMORIES OF IMMIGRATION}

Chorus of Mushrooms describes the relationship between three generations of women and their attitudes towards their situation as Japanese immigrants living in Nanton. The grandmother, Naoe, tries to hold onto her roots. She refuses to forget her past and her Japanese culture. Although she can speak English, she refuses to use the English language that her family has adopted. On the contrary, her daughter, Keiko, has decided to assimilate into Canadian culture for the sake of her own daughter, Muriel. Keiko speaks only in English, eats Canadian food and tries to dress and behave like a 'white' Canadian woman. According to her mother, Keiko "has forsaken identity [...] Converted from rice and daikon to weiners and beans” (Goto 1997: 13). The different attitude 
adopted by these two characters is highlighted by the different language they use and by the lack of communication between them: "I speak my words in Japanese and my daughter will not hear them. The words that come from our ears, our mouths, they collide in the space between us” (Goto 1997: 4).

Naoe tries to prevent the complete loss of her culture by continually speaking out loud in her tongue. She tells Japanese legends, speaks about her past, and gives her opinion about her life in Canada. Through her memories and the tales she narrates, Naoe constructs a sense of home inside of her. As she explains, "You cannot move to a foreign land and call that place home because you parrot the words around you. Find your home inside yourself first, I say. Let your home words grow out from the inside, not the inside in" (Goto 1997: 48).

Muriel, or Murasaki, as her grandmother calls her, is the only one of them who was actually born in Canada. In spite of this, she is still perceived as an outsider because of her physical complexion. She is alienated from a Canadian culture which considers her as foreign, but also from the Japanese background, as she cannot speak or read the language. It is only later, that she will decide to learn the Japanese tongue.

The three perspectives embodied by these characters are highlighted in an article, inserted in the text, and entitled "The Multicultural Voices of Alberta, Part 4: Japanese Canadians Today” (Goto 1997: 189). Keiko explains her decision of forgetting her Japanese identity in order to feel at home in her new country: "You can't be everything at once. It is too confusing for a child to juggle two cultures. Two sets of ideals. If you want a child to have a normal and accepted lifestyle, you have to live like everyone else” (Goto 1997: 189). However, Murasaki's account challenges her mother's perspective:

Life is hard in Canada, once you come to an age when you find out that people think certain things of you just because your hair is black and they have watched 'Shogun, the Mini Series.' [...] I wasn't given the chance to choose. I feel a lot of bitterness about how I was raised, how I was taught to behave. I had a lot of questions about my heritage, but they were never answered. The place where we lived didn't foster cultural difference. It only had room for cultural integration. If you didn't abide by the unwritten rules of conduct, you were alienated as an other, subject to suspicion and mistrust (189).

She has been deprived of the possibility of getting to know her family's culture. What is more, her mother's insistence on rejecting her Japanese roots implied that there was something wrong with them. Thus, Murasaki avoided speaking with the Vietnamese 
labourers who worked on her father's farm. She also avoided speaking with the Chinese boy that attended her school because "Oriental people in single doses were well enough, but any hint of a group and it was all over” (Goto 1997: 125).

Institutions in Canada only provide stereotypical images of the Other. When Muriel goes to Sunday school, she observes the pictures drawn on the song boards. There are pictures of "Indians with feathers", "black boys with curly hair wearing only shorts", “yellow people with skinny eyes”, and a "blonde girl with long eyelashes with a normal dress on" (Goto 1997: 59). The teacher tells the pupils that "Everybody is the same [...] Jesus doesn’t see any difference at all. He loves you all the same” (Goto 1997: 59). By not recognising any difference, cultural specificity is erased and the Other is apparently placed in a central position from which he is paradoxically banned. The use of stereotypes and the denial of cultural diversity are both unsatisfying discourses to approach alterity.

The narrator stresses the importance of acknowledging and respecting cultural difference. As Muriel points out: "I thought that Jesus must be pretty blind if he thought everybody was the same" (Goto 1997: 59). Through the different stories inserted in the novel, Goto tries to deconstruct cultural stereotypes and to present them as other stories, the truth of which can be questioned.

The novel highlights how representations of alterity always entail exotic details that make the Other interesting as well as alien. People ask Murasaki whether her grandmother had to bind her feet, although feet were never bound in Japan. Asian cultural distinctions are obliterated. Muriel is frequently considered Chinese or treated as an oriental woman because of her appearance. Even people of Japanese background use the depreciative terms and representations applied to them: “you're pretty cute for a Nip. He said. Most Nips are pretty damn ugly. All that inbreeding [...] And I felt really funny inside, him saying Nip and everything. Because he was one too” (Goto 1997: 53). The will of many immigrants to assimilate into Canadian culture leads them not only to erase their roots, but also to become intolerant towards other immigrants. As Marc Colavincenzo has also highlighted, this novel shows how "behind a rhetoric of multicultural acceptance Canadian culture is shot through with racism, non-acceptance, and homogenizing or assimilationist tendencies” (2005: 224). Keiko and her husband 
have given up their roots. Keiko pretends to be “as white as her neighbour” (Goto 1997: 29). Her insistence on becoming an Other, goes to the extent of washing her daughter's hands frantically when observing that they are yellow after having eaten some candies: “Yellow, she’s tuningyellow she’s turningyellow she’s -” (Goto 1997: 92). When a schoolteacher tells her that Muriel should wear a blonde wig in order to perform the part of Alice in Wonderland in a school operetta, Keiko is more than willing to dye her daughter's hair: “That way, Muriel can really grow into her role as Alice. She can live and be Alice before opening night!” (Goto 1997: 177).

The façade she tries to create also implies changing names: her name is Keiko but she asks the others to call her Kay; her husband "Shinji” becomes "Sam”; and she gives her daughter an 'occidental' name, Muriel. Keiko also provides nicknames for the Vietnamese people who work on the farm because she thinks "their real names are too hard to pronounce and no one will be able to remember them” (Goto 1997: 34).

Names are essential in the novel and the characters change their names according to their shifting identities. Muriel prefers to be named Murasaki in order to acknowledge her Japanese background. Naoe becomes Purple at the end of the novel. According to Mari Sasano, the characters "adopt new names to suit their identities, creating a movement between what each is born with and what each eventually chooses to become” (1998: 40). The name is also at the origin of the situation of Naoe's family, as her father lost his fortune by stamping his name on a legal document. As Naoe states: “The name begins the story” (Goto 1997: 49).

The separation from the original culture is also stressed by the lack of a surname. Keiko and her husband forgot their real surname when they gave up their roots. The only Japanese word he could remember was the name of a meal, "Tonkatsu" which they adopted as their own surname in Canada. Murasaki's father explains that the word is not entirely Japanese: “tonkatsu isn’t really a purely Japanese word. Ton, meaning pork, is Japanese, but katsu is adopted from 'cutled', and I don't know the origins of that word” (Goto 1997: 209). As Lisa Harris has also observed, “Goto seems to be suggesting that notions of authenticity tied to a particular place are always socially constructed and subject to change. They must therefore be understood as part of an ongoing process of negotiation” (Harris 2008: 26). 
The third part of the novel consists of only a page, which represents everything that has been lost or forgotten: "Part three. Everything that is missing or lost or caught between memory and make believe or forgotten or hidden or sliced from the body like an unwanted tumour” (Goto 1997: 159). It represents the unnameable, the missing part in an immigrant story, the things that have been forgotten or retold in another way, everything that has been erased from memory in the transition of becoming an Other.

Keiko and her husband have chosen to forget and their personality has changed because of this decision. They become, as Pilar Cuder-Domínguez et al. have pointed out, "mere shadows of the full beings they could have been”, since their effort to be accepted and to assimilate into 'white' Canadian culture only results in silence and invisibility (2011: 106 and 111). Shinji used to speak a lot in his youth, and suddenly he feels he is "half a person” (Goto 1997: 207). As he explains: "I was ashamed. I felt a loss so fine it pierced my heart. Made it ache. So I stopped talking” (Goto 1997: 207). Similarly, Keiko ends up with a nervous breakdown when her mother leaves. Naoe was indeed the only person that tried to preserve her cultural background through stories and memories. When she leaves the house, Keiko stops talking and remains in bed. She only recovers from her depression after wearing Japanese night clothes and eating Japanese food. Her husband also feels better when reading Japanese books and eating salted seaweed paste. It is through memory, food and language that one's culture and identity can be maintained. Throughout the first part of the novel, Naoe describes her youth and the atrocities of the war. The memory of these facts may be lost as her daughter refuses to hear and the younger generations cannot understand the language. Yet, Naoe keeps on talking: "Don't come to me for answers, child, these are only words", she says to Murasaki. However, the importance of the words she utters is constantly implied in the text: "The words of an old woman can change little in this world and nothing of the past [...] I only know I must" (Goto 1997: 21). According to Muna Shafiq, "Naoe’s incessant communication in Japanese symbolically (re)constructs and (re)asserts the collective voice of Japanese Canadians” (2006: 6).

The language of Naoe is a "language of memory, pain, desire" (Goto 1997: 129). Her words allow her to preserve a link with her culture and to depict her past. Her Japanese background is however not free from criticism and Naoe's words do not hesitate to question the injustices she saw in her childhood and youth. She describes the social 
injustices that existed in Japan and in China before the war. She also criticizes the sexist treatment of women in that country. Her constant discourse is also a way to make up for a silent past in which she didn't dare to question social injustices: "the pain of not having spoken, of not bothering to ask questions, still aches inside me now”, she says (Goto 1997: 46). The words she utters as an old woman are the words of a wisdom acquired year after year:

\footnotetext{
There are ages of silence and ages of roaring. When I was young and beautiful, my lips were an ornament upon my face. Now my face is crumpled with care and seams adorn my cheeks. My mouth bursts wide and the words rush out, a torrent of noise and scatters. An old woman on a wooden chair might not be much to look at, but step inside her circle of sound and fall into a tornado (24).
}

The same idea is repeated some pages later and stresses the importance of the character's discourse: "If an old woman sits in a chair and never gets out and talks and talks and talks, don't ignore her. She might be saying something that will change the colour of your eyes” (Goto 1997: 37).

Yet, nobody understands the language she speaks. As she says, "My words are only noises in this place I call a home” (Goto 1997: 11). However, these last words also highlight that, in spite of all, she does consider her house in Nanton "a home”. In fact, it is interesting to observe the evolution of the character's attitude towards the Canadian wind. The beginning of the first part of the novel stresses Naoe's dislike for "this unrelenting, dust-driven, crack your fingers dry wind” (Goto 1997: 3). She tries to fight against the noise of the wind with the sound of her words. As the novel progresses, Naoe also remembers Japanese winds. First, she recalls a "non-wind" that characterized the summers of her childhood in Japan, which are described as "A breathless time of sucking air like water” (Goto 1997: 69). Later, she remembers another wind, called "kama itachi. An evil wind that moves with the speed of a weasel and cuts with the sting of a scythe” (Goto 1997: 75). Through her narrative, she acknowledges that Japanese winds can be as threatening as the Canadian prairie wind. When she leaves the house and accepts to move on, her opinion about the Canadian wind changes: "Funny how I hated the wind so, when I was sheltered from it. We are sisters, you and I, and your cool breath upon my cheeks will comfort me” (Goto 1997: 81).

It is only after remembering and narrating her memories that Naoe feels free to leave the house: "Useless to waste time on sentimental memory. I may be an old fool, but 
stupidity is another matter. So important to remember, but say the words out loud. Don't wallow in pools of yesterday, I say. Don’t drown in yesterday’s tears” (Goto 1997: 74).

At the end of the novel, Naoe takes part in a rodeo, and rides a bull like a cowboy. Through this image, the text stresses the absurdity of stereotypes and highlights the character’s transformation. As Mari Sasano has observed:

[Naoe] has infiltrated the ranks. While furiously not white Canadian, she fully embraces and occupies aspects of that culture that please her. Entering in means that the centre is neither sealed nor exclusive. Membership changes, and as it does, the norm is altered. By challenging expectations and by living outside of the fear of being detected as abnormal, it is possible to carve out a new space of belonging while remaining truthful about the differences that do exist (1998: 51)

If Naoe's success as a bull rider may signify her appropriation of a male Western Canadian tradition, her success is nuanced by the fact that she is wearing a mask, as Eva Darias Beautell has argued (2003: 40). Nevertheless, Naoe progressively becomes closer to Canadian culture just as Keiko accepts the introduction of Japanese food in her house.

Food is essential in this novel, where one seems to be what he eats. As the shop assistant states: “Eating's a part of being after all” (Goto 1997: 138). According to Heather Latimer, "eating is a gendered and racialized act that constantly informs how the characters see themselves emotionally and psychologically” (2006: 1). Although there isn't any Japanese food in Keiko's kitchen, Naoe manages to get some sent by her brother and to hide it in her room. It is through food and language that she tries to preserve her culture. She shares the food with Murasaki, just as she tells her stories from Japan in a language the child cannot speak. The grandmother's bed becomes a "bed of feasts”, a "bed of tales” (Goto 1997: 18). Lisa Harris has also observed how "Food unites Naoe and Murasaki”. Murasaki "learns to use food and language as tools to shape her own version of a Canadian future" (Harris 2008: 24). She cannot speak Japanese nor hold her chopsticks properly: "I know. I don’t hold my pen properly either. But I can still write. And I can still eat”, she says (Goto 1997: 121). According to Murasaki, eating is an important way of getting to know a culture:

\footnotetext{
There are people who say that eating is only a superficial means of understanding a different culture. That eating at exotic restaurants and oohing and aahing over the food is not even worth the bill paid. You haven't learned anything at all. I say that's a lie. What can be more basic than food itself? Food to begin to grow? [...] But don’t stop there, my friend, don't stop there, because food is the point of departure. A place where growth begins" (Goto 1997: 201).
} 
It is through language and tales that it continues. Words, like food, can nurture, and can be "swallow[ed]" (Goto 1997: 29). They become like the squid which "swells and softens": "I held my words inside my mouth until they swelled and softened" (Goto 1997: 18), says Murasaki. Listening to the sound of foreign words becomes a way to discover and imagine another cultural background.

\section{LANGUAGE}

Words appear in the novel as material elements which can "take form and live and breathe among us. Language is a living beast” (Goto 1997: 99). They seem to have a life of their own, one that the self cannot control. They can "change shape and size", "grow arms and legs", and weigh heavily, as the memory of the characters: "Words, words, words, WORDS. Ahh, words grow heavier every day, upon my bony back”, says Naoe (Goto 1997: 21).

The text includes many words in Japanese and does not provide their translation into English. The reader is thus put in the position of an outcast, unable to have access to the content of the words. Our expectations of resolving difference into unity, or as Hutcheon would say, of trying to "absorb the margin into the centre" (1988: 11) are thus frustrated. As Murasaki listens to the words uttered by her grandmother without understanding them, the reader sees the signifiers and can only guess or imagine their meaning. Hiromi Goto has explained why she decided not to provide any translation:

I wanted to highlight that difference exists, all cannot be understood, language could and can be a barrier. This is based on my assumption that most of my readers are Englishspeaking and do not understand Japanese. This is the audience the book is mainly speaking to [...] (Goto 1996: 112)

As Muna Shafiq has pointed out, "this strategy obliges the unilingual dominant language reader to seek meaning outside the dominant language” (2006: 8). Yet, the materiality and the sound of the words introduce the reader to the other culture, as a child learning some aspects of the language by immersion. Language appears as a constraint but also as a meaningful way of arousing interest towards what is unknown and foreign. Although Murasaki cannot understand the language used by Naoe, communication still takes place through body language:

She cannot understand the words I speak, but she can read the lines on my brow, the creases beside my mouth. I could speak the other to her, but my lips refuse and my tongue 
swells in revolt. I want so much for someone to hear, yet it must be in my words (Goto 1997: 15).

The reader is encouraged to think about translation and about how different languages do not have exact equivalents for some concepts. When learning Japanese, Murasaki realizes there is no word to express love "except to a spouse or lover" (Goto 1997: 54). Naoe also sees that the English word “water” doesn’t indicate whether the water is cold or warm, whereas the distinction is made clear by the Japanese words "Mizu" and “Oyu” (Goto 1997: 170). According to Murasaki, the good thing about speaking several languages is that it allows you to fill these gaps: “when there isn't one word in English, it will be there in Japanese and if there's something lacking in your tongue, I'll reach for it in English. So I say to you in English. I love you, Obachan” (Goto 1997: 54). As Mari Sasano has highlighted:

\section{Rather than being suspended half-in-half-out of two cultures, Murasaki actually has an edge over either: she slips between them as easily as a salamander inhabits water and land. [...] Contrary to Keiko's philosophy of childraising, Murasaki benefits from, instead of being confused by, the juggling of two cultures (1998: 42).}

In her childhood, Murasaki couldn't speak nor understand the Japanese language. In spite of this, the Japanese words pronounced by her grandmother meant more to her than the conversations in English she had with her parents: "the things we talked about would never have the power to linger. 'How was school?' and, 'Pass the gravy boat,' were sad substitutes for my malnourished culture” (Goto 1997: 99). She imagined what her grandmother said in Japanese. A new kind of communication was created through her imagination: “I couldn’t understand the words she spoke, but this is what I heard. Mukashi, muhashi, omukashi... Listen Murasaki, listen” (Goto 1997: 18).

It is interesting to see how the sound of the words itself becomes poetry and seems to have an incantatory value:

I turned my head slowly in Obachan's lap, the fabric scratch and stiff. Inhaled dust and poetry. She stroked my forehead with her palm, and her words, they flowed fluid. I snuggled close and curled my legs and stopped pretending to understand. Only listened. And listened. And then my mouth opened on its own accord and words fell from my tongue like treasure [...] Obachan and I, our voices lingered, reverberated off hollow walls and stretched across the land with streamers of silken thread” (Goto 1997: 52 and 20)

The importance of language and of the two voices speaking together is stressed by the repetition of this same paragraph in the novel. Communication can still take place in spite of the language used and even if the interlocutors are not together, i.e. "over distance and time” (Goto 1997: 139). The characters can "hear” each other’s "thoughts" 
(Goto 1997: 114). The text defies normal realist logic. Language can be learnt or suddenly forgotten. Keiko's husband can read books in Japanese but he cannot speak the words out loud nor remember his name. Murasaki knows what some Japanese words “mean” but she doesn’t know “what they are” (Goto 1997: 136). The narrator also plays with antiquated English words such as "league” or "fortnight”. As Patricia L. Gantzert has observed, "They have no specific meaning for Naoe or Murasaki, emphasizing the indefiniteness of any word. 'Whatever that means' is a phrase Murasaki often uses in her questioning discourse” (1997: 32).

As the novel goes on, language is treated in a more surrealist way. Naoe leaves the house and starts speaking in English with a cowboy who has a strong English accent. She even starts speaking herself with this accent just as he loses his own: "Sher", she says (Goto 1997: 112). However the reader cannot be sure about the language or the accent that is being used, since the characters are not sure about it either. As Mari Sasano has observed, "Language becomes unconscious. [...] Naoe, when she has developed more of a rapport with Tengu, remarks that his cowboy accent is gone, but in fact he didn't have one to begin with; she has inserted the accent to fit with her preconceptions of him” (1998: 43).

At the beginning of the novel, the controlling-narrator states that she will tell the story in Japanese. Therefore, the English used in the text implies that one layer of translation has been introduced. However, the narrator herself thinks she has been speaking in English all the time. “Haven’t we been talking Japanese all along?”, her lover reminds her (Goto 1997: 196-197). The reader cannot be sure of the language that is actually being spoken nor of the identity of the different characters. Pilar Cuder-Domínguez et al. have observed how in this novel translation "becomes oddly unnecessary between people speaking different languages, thus intimating true communication beyond words, whereas at other times translation allows for metamorphosis, change, and progress, resulting in a fluid, unfixed subjectivity” (2011: 138-139).

The lives of Murasaki and Naoe seem to mingle. They both leave home and have a cowboy lover whom they abandon afterwards. This fusion is also encouraged by Naoe who says to Murasaki: "Why don’t I talk sometimes and you just move your lips and it 
will look like you're the one who's talking” (Goto 1997: 127). Naoe chooses to be called Purple, the English translation of Murasaki:

'So, who is Murasaki and who is Purple?'

'The words are different, but in translation, they come together.'

'So you're a translation of Murasaki and Murasaki is a translation of you?' [...]

'That's one reading of it' (Goto 1997: 174)

As Steve McCullough has observed, in the novel "proper names proliferate identities and problematize the notion of textual origins instead of simply positioning coherent selves in cultural-linguistic worlds” (2003: 160). The narrator plays with the notions of transition and translation to show that the characters' identities evolve throughout the novel, but also shift and merge according to linguistic and cultural factors. Muna Shafiq has also highlighted how Goto "constructs hybrid narrative identities that stand in opposition to and challenge notions of authenticity based on pure cultures" (2006: 8). There is not one identity, but several. Naoe thinks about a philosopher who dreamt he was a butterfly dreaming that he was a philosopher: “And when he woke up, he didn't know if he was a philosopher or a butterfly. What nonsense. This need to differentiate. Why, he was both, of course” (Goto 1997: 44). Naoe and Murasaki are characterized by different identities which coexist in a variety of degrees. As Pilar Cuder-Domínguez et al. have stated:

\footnotetext{
Rather than being crippled by the memories of a traumatic past, [Naoe] is so empowered that she comes to symbolize a wealth of future possibilities [...] Naoe embodies the power of the tale and the storyteller to create new life and endow the current one with new meanings (2011: 99).
}

The novel contains different stories and legends which intertwine with the character's experiences. These appear as additional mirrors which echo the character's lives. As Muna Shafiq has observed, the characters "employ the oral tradition of telling stories to reinvent themselves as bicultural (Canadian and Japanese) women, celebrating their ethnic differences (2006: 5).

\section{THE IMPORTANCE OF STORYTELLING}

As she did not understand what her grandmother said in Japanese, the controllingnarrator is imagining the stories told by Naoe. The narrator is not trustworthy. We know she lied to her friend Patricia and invented what her grandmother was saying. As she affirms, "I'm making up the truth as I go along" (Goto 1997: 12). She is not even sure 
of the reliability of what she tells: "Did I just make that up or is it true? I don't even know anymore. Saying it out loud can make it so" (Goto 1997: 53). Sometimes she directly admits having lied: “That’s a lie. One of many, I suppose” (Goto 1997: 98). However, as we have seen, the notion of truth is subverted in the novel. It appears as a concept which is always under construction and negotiation. The emphasis is put on the telling, and particularly on the re-telling. In the "Acknowledgements" of the novel, Goto states: "In the process of re-telling personal myth, I have taken tremendous liberties with my grandmother's history. This novel is a departure from historical 'fact' into the realms of contemporary folk legend. And should (almost) always be considered a work of fiction”. She is “re-telling” the life of her family in the novel, just as Murasaki is "retelling and re-creating” the story (Goto 1997: 185). As Goto has explained:

\footnotetext{
Our worlds no longer exist in isolation. The arts are a place where cultures and stories can intersect, overlap. [...] I've rewritten Japanese traditional folk tales with a North American feminist sensibility. [...] I make sense of my world with the instruments of the cultures I've inhabited. I feel lucky in that I'm in a position to choose the best of both worlds (Goto, in Morris 2008: 235).
}

Julia Kristeva has observed that "any text is constructed as a mosaic of quotations, any text is the absorption and transformation of another” (1980: 66). Memories and legends entwine in Murasaki's account. As the character explains, "It's funny how you can sift your memories, braid them with other stories. Come up with a single strand and call it truth” (Goto 1997: 93).

The intertexts inserted in the novel present contrasting points and therefore insist on multiplicity. Many of the legends told echo the character's stories. The tale of an old woman that must be abandoned by her family recalls Naoe's position as an old woman who is going to be sent to an old people's home. The legend of a family that could not have children reminds that of Naoe's brother, who has not been able to have descendants. An encounter at an airport becomes “another airport story” (Goto 1997: 53). Myth, legend and reality are mixed. As Hutcheon has pointed out, novels "renarrate and re-conceptualize the past, both literary and historical, and thereby reformulate the possibilities of subjectivity narrated in them” (1988: 8-9).

Stories are constructed in a way that is similar to the technique used in a Japanese legend by two characters named Izanami and Izanagi. They create a new home just by pronouncing the words out loud: “'We are gods [...] We can create'[...] 'There are no 
rules,' Izanami chanted, and saying it aloud made it so" (Goto 1997: 30). In this legend, in which the two children create Japan, one of them exclaims "Let there be light!" and is immediately reprimanded by his sister”. Patricia L. Gantzert has observed how the narrator makes reference to Eastern and Western texts and beliefs: "Pokes at master narratives of Western society, such as those of Shakespeare (1997: 69, 175) and the Bible, shake up the assumptions often association with them or situate their 'truths' in new relations” (1997: 31).

When Naoe leaves, Murasaki realizes how people are looking forward to hearing exotic tales: “everybody, including me, was always looking for a story. That the story could be anything [...] the story can be anything, but there have to be details. People love details. The stranger, the more exotic the better” (Goto 1997: 89). Through the stories they hear, they construct their preconceived ideas about other cultures. As Murasaki points out, “people want to hear a story, and then, after they're done with it, they can stick the story back to wherever it came from" (Goto 1997: 1). However, the multiple perspectives provided by the narrative disrupt these expectations and make it impossible for the reader to draw a stereotypical conclusion from the text. The different points of view, the mixture of facts and legend, of reality and imagined or invented parts show how a story is not an establish set of notions: "Funny thing, Murasaki, how these stories keep changing”, says Naoe (Goto 1997: 73). As this character points out: "this is not the story I learned, but it's the story I tell. It is the nature of words to change with the telling. They are changing in your mind even as I speak” (Goto 1997: 32) Thus, telling a story implies creation, but also re-creation, and the characters and facts change with the telling: "It can't really be you once I make it a story. It becomes someone else, you know?”, says Murasaki (Goto 1997: 55).

Telling stories is also a way of creating human ties. As Naoe says:

[...] stories are shared. [...] there is a partnership in the telling and listening, that it is of equal importance [...] If the positions become static, there can never be stories. Stories grow out of stories grow out of stories. Listening becomes telling, telling listening (Goto 1997: 172).

Whereas her mother “didn't tell tales at all”, the stories told by Naoe fostered a deeper link between her and Murasaki, who wanted to "hear bedtime stories, hear lies and truth dissembled” (Goto 1997: 29). The importance of telling one’s story is highlighted by 
the way Murasaki imagines her mother’s tales: "Her stories must be ugly things filled with bitterness and pain. The pain of never having told” (Goto 1997: 32).

It is interesting to see that Murasaki is named after an important Japanese writer, Murasaki Shikibu, who is considered to be the first person to write a novel and to “create the antihero” (Goto 1997: 165) in her work, The Tale of Genji. As Patricia Gantzert has pointed out, The Tale of Genji “offers an important model of courageous achievement in the face of restrictive conditions”. This work may thus offer Murasaki a valid representation upon which to build a positive image of herself as a JapaneseCanadian woman (1997: 63).

By mixing different stories within the novel, Chorus of Mushrooms questions the established notions that surround immigration, and it tries to create a different kind of account. “An immigrant Story With a Happy Ending. [...] Nothing is impossible. Within reason, of course”, says Murasaki (Goto 1997: 159). As Mari Sasano has affirmed, "Muriel/Murasaki ana Naoe are attempting, in their retelling of folktales, as well as in the living of their lives, to unlock themselves from the expected unhappy endings”. Part Three, “An Immigrant Story With a Happy Ending” (Goto 1997: 159) is, as Sasano states, a "page-long non-story waiting to be written into existence” (1998: 46). Part Four shows how the experience of immigrants can be characterized by a happy ending. However, by introducing racist texts at the end of the novel, this perspective is attenuated, and recalls the tragic alternatives that may await them.

\section{REFERENCES}

Colavincenzo, M. 2005. “'Fables of the reconstruction of the fables”: Multiculturalism, postmodernism, and the possibilities of myth in Hiromi Goto's Chorus of Mushroms”. In Davis G. (Ed.) Towards a Transcultural Future: Literature and society in a 'post'-colonial world. New York: Rodopi, 223-230.

Cuder-Domínguez, P., Martin-Lucas, B. and Villegas-Lopez, S. (Eds.) 2011. Transnational Poetics: Asian Canadian Women's Fiction of the 1990s. Toronto: TSAR Publications. 
Darias Beautell, E. 2003. “Hiromi Goto’s Chorus of Mushrooms: Cultural difference, visibility and the Canadian traditon”. Revista Alicantina de Estudios Ingleses 16, 6-50.

Gantzert, P. 1997. "Throwing voices: Dialogism in the novels of three contemporary Canadian women writers”. Unpublished Thesis submitted in the Department of English of the University of Manitoba.

Goto, H. 1996. “Translating the self: Moving between cultures”. West Coast Line 30 (2), 111-113.

Goto, H. 1997. Chorus of Mushrooms. London: The Women’s Press.

Harris, L. 2008 “Eating and reading Hiromi Goto”. Cuizine: The Journal of Canadian Food Cultures 1 (1). 24 January $2012<$ http://id.erudit.org/iderudit/019372>

Hutcheon, L. 1988. The Canadian Postmodern: A Study of Contemporary EnglishCanadian Fiction. Toronto: Oxford University Press.

Kristeva, J. 1980. “Word, dialogue and novel”. In Roudiez L. (Ed.) Desire in Language: A Semiotic Approach to Literature and Art. New York: Columbia University Press, 64-91.

Latimer, H. 2006. "Eating, abjection, and transformation in the work of Hiromi Goto". Thirdspace: A Journal of Feminist Theory \& Culture, 5 (2). 24 January 2012 $<$ http://www.thirdspace.ca/journal/article/view/latimer>

McCullough, S. 2003. “'Trust Me': Responding to the threat of writing in Chorus of Mushrooms”. English Studies in Canada 29 (1-2), 149-170.

Morris, R. 2008. "Braiding race politics and narrative form: An interview with Hiromi Goto”. In Looking through the twin lens of race and gender: a new politics of surveillance in Asian Australian and Asian Canadian women's writing. Unpublished Thesis submitted at the University of Wollongong.

Sasano, M. 1998. "Words like Buckshoot: Taking aim at notions of nation in Hiromi Goto’s Chorus of Mushrooms”. Open Letter 10 (3), 38-53.

Shafiq, M. 2006. “Linguistic hybridity in Gloria Anzaldúa’s Borderlands, Antonia d'Alfonso's Avril Ou L’Anti-Passion, and Hiromi Goto's Chorus of 
Mushrooms”. In Gonzalez M. and F. Tolron (Eds.) Translating Identity and the Identity of Translation. Newcastle: Cambridge Scholar Press, 3-19.

Smith, E. 2007. “'Can you listen before you hear?': Responsible reading and the politics of second-person narration in Hiromi Goto’s Chorus of Mushrroms”. Visions of Canada. Canadian Studies in Europe 6, 251- 267.

Received: 25 February 2012

Accepted: 29 March 2012

Cite this article as:

Pich Ponce, E. 2012. "Memory and language in Hiromi Goto's Chorus of Mushrooms". Language Value 4 (2), 70-88. Jaume I University ePress: Castelló, Spain. http://www.erevistes.uji.es/languagevalue. DOI: http://dx.doi.org/10.6035/LanguageV.2012.4.2.6

ISSN 1989-7103

Articles are copyrighted by their respective authors 